\title{
A New Method of Creating Technology/Function Matrix for Systematic Innovation without Expert
}

\author{
Tien-Yuan Cheng'
}

\begin{abstract}
The technology/function matrix is comprised by specific technologies and functions, and through the technology/function matrix we can known what the technologies with functions have opportunities for innovation of product or technology. However, the technology/function matrix is very difficult to create, because the patents need to be read, analyzed and categorized into the technology/function matrix always more than hundreds or thousands. In this research, I propose a method to create a technology/function matrix just need to execute patent search without reading and analyzing patents. Through the proposed method anyone can create a technology/function matrix in a short time without experts' help even if there are thousands of thousands of patents need to be read and analyzed.
\end{abstract}

Keywords: Technology/function matrix; patent map; patent search; patent classification; systematic innovation.

\footnotetext{
' Legal/IP Department of Delta Electronics, Inc. 4F., No. I0, Huzhu St., Banqiao Dist., New Taipei City 22048,Taiwan (R.O.C.) 886-9I2026957 Email:iamkevincheng@gmail.com
} 


\section{Introduction}

Patent map is to collect patent information from patent specification for a specific purpose of use, and assembled, analyzed and drew in a visual form of presentation such as a chart, graph, table or matrix (Shin-Ichiro Suzuki, 20II). Patent map helps us to select subject for research and development, pick out new ideas for innovation, and gain information of competitors' technology development for making strategy. Patent map has two major types, one is the technology map and another one is the management map. The management map is the statistic of assignee, country, application date, publication date, IPC (international patent classification), USPC (US patent classification), citation or other bibliographies of patent (Byung-Un Yoon, Chang-Byung Yoon and Yong-
Tae Park, 2002). Usually, the technology map is a matrix like assignee/IPC matrix, assignee/USPC and technology/ function matrix and so on.

The management maps help managers to known trends of the target technology (Zan Huang, Hsinchun Chen, Alan Yip, Gavin Ng, Fei Guo, Zhi-Kai Chen and Mihail C. Roco, 2003). See the figure I, it is the statistic of patent application date and draws in graph. The figure I shows that development of wind power technology starts from 1978 and the development have gone down a little form 1980 to 1996, but it has a sharp increase in patent application after 1996. It shows the development trend of wind power technology (WIPO, 2009).

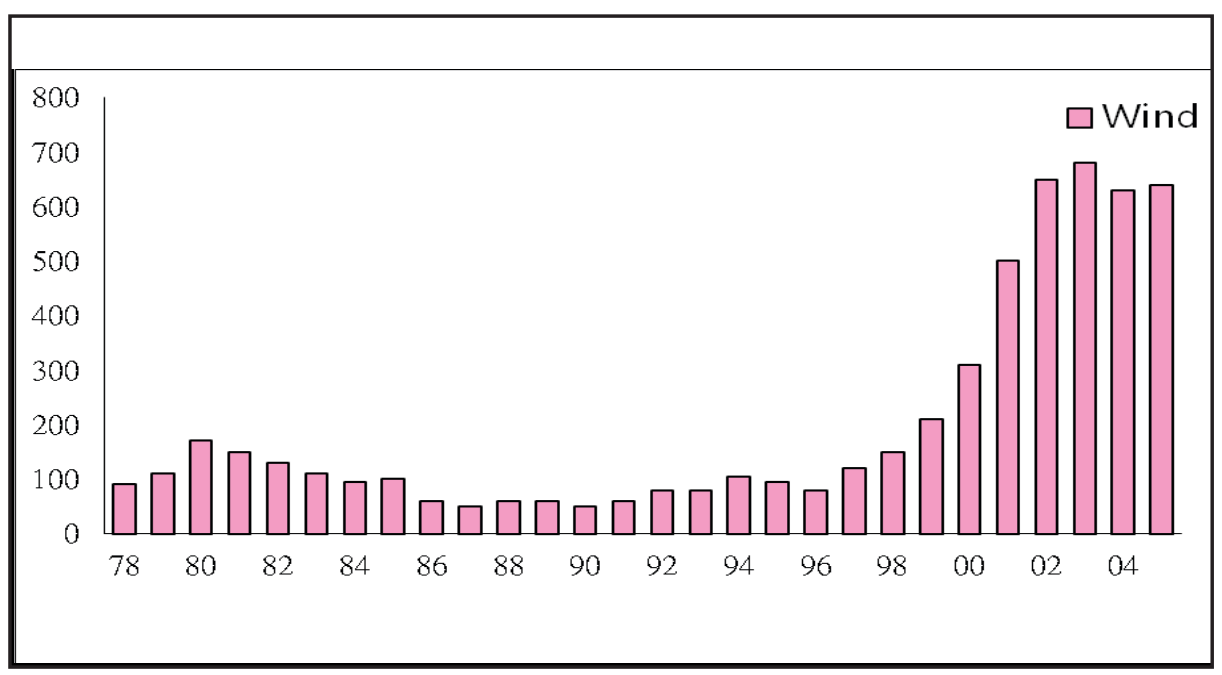

Figure I: Applications date for wind power technology. Data from WIPO - Patent-based Technology Analysis Report (2009)

The technology maps help managers, R\&D people and engineers to know the development of target technology or product (Holger Ernst, 2003). For example, the technology/function matrix shows what the development phase of technology with function, and what the technology with function have opportunities or ricks. Managers, R\&D people and engineers can make decision for development of technology or product base on the technology/function matrix.
The steps of creating a technology/function matrix are patent search, reading, analyzing and categorizing patents into all fields of technology/function matrix. It usually needs experts to help especially in reading, analyzing and categorizing patents (Young Gil Kim, Jong Hwan Suh and Sang Chan Park, 2008). The table I is a technology/ function matrix of "nano-composite material" subject. The matrix shows the field of "Polymer" technology with "Mechanical and dimensional stability" function is developed more mature because patents in this field are more than other fields of technology with function (HsinNing Su and Pei-Chun Lee, 2009). 


\begin{tabular}{|c|c|c|c|c|c|c|c|}
\hline & & \multicolumn{6}{|c|}{ MATRIX MATERIAL } \\
\hline \multirow{13}{*}{ 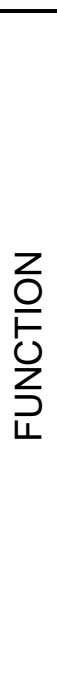 } & & Polymer & Clay & Ceramic & Metal & Other & Total \\
\hline & Mechanical dimensional stability & 176 & 4 & 59 & 35 & 11 & 285 \\
\hline & Permeability & 52 & 1 & 1 & 0 & 1 & 55 \\
\hline & Thermal stability & 70 & 1 & 16 & 13 & 3 & 103 \\
\hline & Flame retardancy & 19 & 0 & 0 & 0 & 1 & 20 \\
\hline & Chemical resistance & 17 & 0 & 5 & 4 & 4 & 30 \\
\hline & Surface appearance & 6 & 0 & 2 & 0 & 1 & 9 \\
\hline & Electric conductivity & 69 & 0 & 28 & 30 & 21 & 148 \\
\hline & $\begin{array}{l}\text { Optical and light emitting } \\
\text { property }\end{array}$ & 77 & 0 & 19 & 10 & 15 & 121 \\
\hline & Cement/adhesivity & 7 & 0 & 1 & 0 & 0 & 8 \\
\hline & Magnetic property & 10 & 0 & 7 & 28 & 0 & 45 \\
\hline & Other & 56 & 2 & 20 & 19 & 23 & 120 \\
\hline & Total & 503 & 6 & 138 & 120 & 57 & 824 \\
\hline
\end{tabular}

Table I:Technology/Function Matrix of "nano-composite material”. Data from Hsin-Ning Su and Pei-Chun Lee (2009)

To create the management maps is easy. First, make sure the key words of subject and using the key words for patent search. Second, gathering statistics of the patent information search out by patent search. And the last step is using the statistics of patent information to draw graphs. For example, we can gather statistics of patent application date and using the statistics to draw a run chart for understanding the technology development trend.

However, creating a technology/function matrix is very difficult. The first step of traditional method of creating a technology/function matrix is deciding search terms which are the technology or function terms of the subject (Young Gil Kim, Jong Hwan Suh and Sang Chan Park, 2008). For example, if the subject is "nano-composite material" and then the search terms could be "nano" and "composite" appeared in title or abstract (Hsin-Ning Su and Pei-Chun Lee, 2009). The second step is creating the technology category and function category (Young Gil Kim, Jong Hwan Suh and Sang Chan Park, 2008). For example, for the "nano-composite material" subject, the technology category includes Polymer, Clay, Ceramic and Metal, and the function category includes "Mechanical and dimensional stability", Permeability, "Thermal stability", "Flame retardancy", "Chemical resistance", "Surface appearance" and etc (Hsin-Ning Su and Pei-Chun Lee,
2009), but the second step usually needs experts' help, because experts know what the major technologies and functions of the subject. And the last step is reading, analyzing and categorizing patents search out by patent search into the technology/function matrix by manpower (Young Gil Kim, Jong Hwan Suh and Sang Chan Park, 2008). In this step we need to read and analyze what the technologies and functions of patents, and then categorize patents into fields of the technology/function matrix. For accuracy of categorizing patents into the technology/ function matrix we always need experts' help (YuenHsien Tseng a, Chi-Jen Lin b and Yu-I Lin, 2007). It is a heavy workload to read, analyze and categorize patents into the technology/function matrix, especially when the patents are more than thousands. The heavy workload is the main reason of why a technology/function matrix is difficult to create.

Another problem of traditional method is that it is difficult to build the technology category and function category without experts' help, needless to say reading, analyzing and categorizing more than thousands patents into a technology/function matrix. Accordingly, without experts' help creating the technology/function matrix is being a mission impossible. 


\section{Proposed Method}

In this research, I propose a new method to create a technology/function matrix without help of expert or the person having ordinary skill in the art. Through the proposed method, we don't need experts' help for creating the technology category and function category, and reading, analyzing and categorizing patents into the technology/function matrix. We just need to execute patent search for collecting patents, gathering statistics of the patents' information and then fill in fields of the technology/function matrix with the result of second patent search. It means everyone can create the technology category and function category and categorize patents into the technology/function matrix without experts' help. The steps of the proposed method are below.

\section{Step I: Patent search}

The first step of the proposed method is patent search, and we need to make different patent search strategy for different purpose. For the purpose of study, research or industrial analysis, the patent search strategy will be simple for collecting more enough patents. For example, one case of the research subject is nano-composite material, and then the patent search strategy will be just "nano" and "composite" appeared in title or abstract (Hsin-Ning Su and Pei-Chun Lee, 2009). Another research subject is "solar power inverter", and the patent search strategy is that interaction of inverter and the result of union of events solar, Photovoltaic and "PV" appeared in description of issued patents, and then we search out 6,393 patents (the search date is $201 \mathrm{I} / \mathrm{I} / 109$ and the patent search engine is "Free Patent Online").

However, the purpose of creating a technology/function matrix is for R\&D, design around or patent portfolio, the patent search strategy need to narrow down for fitting the patent search result to the subject. As the "solar power inverter" subject, the patent search strategy is that "(("solar inverter" 3 or "Photovoltaic inverter" 3 and "PV inverter" 3) or ((solar or Photovoltaic) and "DC DC” 2))" appeared in description of issued patents, and then we search out I,697 patents (the searching date is 201 I/II/09 and the patent search engine is "Free Patent Online").

\section{Step 2: Creating technology category and function category}

The second step is creating the technology category and function category. The traditional method needs experts to help to create the technology category and function category according to the subject, but the proposed method without help of experts, R\&D people or person skilled in the art. The proposed method just needs to gather statistics of IPC and USPC of the patents searched out by the first step.

IPC is a kind of patent classification built by WIPO (World Intellectual Property Organization) and the classification of IPC is based on the different areas of technology to patent relate (WIPO, 20II), and the IPC divides technology into eight sections with more than 70,000 subdivisions, and the eight technology sections are "HUMAN NECESSITIES", "PERFORMING OPERATIONS; TRANSPORTING", "CHEMISTRY; METALLURGY”, "TEXTILES; PAPER”, "FIXED CONSTRUCTIONS", "MECHANICAL ENGINEERING; LIGHTING; HEATING; WEAPONS; BLASTING", "PHYSICS" and "ELECTRICITY". IPC is consisted of Section, Class, Subclass, Main Group and Subgroup, and the Sections are the highest level of hierarchy of IPC, and the Subgroups are the detail description of technology of IPC.

USPC is another patent classification built by USPTO (United States Patent and Trademark Office) and the classification of USPC is based on the function, effect, end-product, structure or use of a patent (USPTO, 201I). There are about 450 Classes of patent and about 150,000 subclasses of patent in the USPC. Classes and subclasses have titles which provide a short description of the class or subclass. Classes and subclasses also have definitions which provide a more detailed explanation.

There are at least one IPC code and USPC code distributed to every US patent. For example, the Figure 2 is part of US6657II8 patent specification and it shows the bibliographic data of US6657II 8 patent. Form the Figure 2 we can know that US6657III patent has H0IL2I/33 and HOIL3I/048 two IPC code, and I36/244, I36/25I, I36/29I, I36/293,|36/258, 363/60, 323/906, 323/22I, 60/64|.8 nine USPC code. 


\section{(12) United States Patent} Toyomura et al.
(10) Patent No.: $\quad$ US 6,657,118 B2

(45) Date of Patent: Dec. 2, 2003

(54) SOLAR BATTERY MODULE, METHOD OF MANUFACTURING SAME AND POWER GENERATING APPARATUS

(75) Inventors: Fumitaka Toyomura, Nara (JP); Nobuyoshi Takehara, Kyoto (JP)

(73) Assignee: Canon Kabushiki Kaisha, Tokyo (JP)

(*) Notice: Subject to any disclaimer, the term of this patent is extended or adjusted under 35 U.S.C. 154(b) by 0 days.

(21) Appl. No.: 09/957,945

(22) Filed: Sep. 24, 2001

(65) Prior Publication Data

US 2002/0038666 A1 Apr. 4, 2002

(30) Foreign Application Priority Data

Sep. 29, $2000 \quad$ (JP) ……………………... 2000-300164

(51) Int. Cl. ${ }^{7}$....................... H01L 21/33; H01L 31/048

(52) U.S. Cl. .................. 136/244; 136/251; 136/291; $136 / 293 ; 136 / 258 ; 363 / 60 ; 323 / 906 ; 323 / 221$;

(58) Field of Search …........................... 136/244, 251, $136 / 291,293,258 ; 363 / 60,147 ; 323 / 906$

(56) References Cited U.S. PATENT DOCUMENTS

4,217,633 A $*$ 8/1980 Evans, Jr. ................... 363/27 $4,499,658 \mathrm{~A} * 2 / 1985$ Lewis ......................... 136/251 6,066,797 A $\quad 5 / 2000$ Toyomura et al. ............. 136/251 $2002 / 0038667$ A1 $\quad 4 / 2002$ Kondo et al. ............... 136/293 2002/0050290 A1 * 5/2002 Kobayashi .................... 136/293 FOREIGN PATENT DOCUMENTS

$\begin{array}{lrl}\text { JP } & 11-251614 & 9 / 1999 \\ \text { JP } & 2000-77700 \mathrm{~A} * & 3 / 2000 \\ \text { JP } & 2001-156315 \mathrm{~A} * & 6 / 2001 \\ & \\ & \text { OTHER PUBLICATIONS }\end{array}$

Kurokawa et al, "Conceptual considerations on PV systems composed of AC modules," Solar Energy Materials and Solar Cells, vol. 47, (1997), pp. 243-250.*

"Solar Power Generation System Application Technology Development", 1996 Consigned Operation Result Report of New Energy and Industrial Technology Development Organization (NEDO), Japan Electrical Manufacturers' Association, Mar. 1997, pp. 104-105.

"Solar Power Generation System Application Technology Development", 1997 Consigned Operation Result Report of New Energy and Industrial Technology Development Organization (NEDO), Central Research Institute of Electric

* cited by examiner

Primary Examiner-Alan Diamond

(74) Attorney, Agent, or Firm - Fitzpatrick, Cella, Harper \& Scinto

(57) ABSTRACT

If an inverter is merely attached to the back side of a solar battery module, the inverter becomes an obstacle to transport and installation, it may be broken if it strikes a building structure at the time of installation and it may malfunction owing to impact with an object. Accordingly, a weatherresistant film, a first filler, a solar battery element, a second filler and a back reinforcing material are stacked in the order mentioned and the fillers are melted using a vacuum laminator to thereby seal the solar battery element in resin between the back reinforcing material and weather-resistant film. At this time an inverter is placed on the surface of the back reinforcing material that opposes the solar battery element. Power Industry, Mar. 1998, pp. 148-149.

Figure 2: The bibliographic data of US6657II8

According to the definitions of IPC and USPC, we know that the classification of IPC is base on technologies of patents, and the classification of USPC is base on functions of patents. This is the reason for why the proposed method use IPC as the technology category and USPC as the function category. For the purpose to decide what the IPCs and USPCs to be the technology category and function category, we need to gather statistics of IPC and USPC, and then we choose the IPC and USPC which the counts in TOP 10 or TOP 20, or counts add up to $80 \%$ or $90 \%$ to be the technology category and function category. But the IPCs or USPCs chose by the way may not match our subject. For example, the top IO IPC of the "solar power inverter" subject are H02J, H02M, HOIL, G05F, H0IM, E2IB, G06F, H02P, H02H and B60L, but E2IB (EARTH OR ROCK DRILLING; OBTAINING OIL, GAS, WATER, SOLUBLE OR MELTABLE MATERIALS OR A SLURRY OF MINERALS FROM WELLS) or
B60L (PROPULSION OF ELECTRICALLY-PROPELLED VEHICLES) don't match our subject. For the purpose of matching subject we need to exclude the IPCs and USPCs which we don't interest.

As shown in table 2 and table 3, the IPC and USPC chose for technology category and function category. For reason of understanding the technology category and function category we need to give descriptions to IPC $n$ and USPC $\mathrm{n}$ with short words, because the IPC and USPC classifications just codes can't be understood. 


\begin{tabular}{|c|c|c|c|}
\hline $\begin{array}{l}\text { Technology } \\
\text { code }\end{array}$ & IPC Class & IPC Description & Technology Term \\
\hline T1 & H02J & 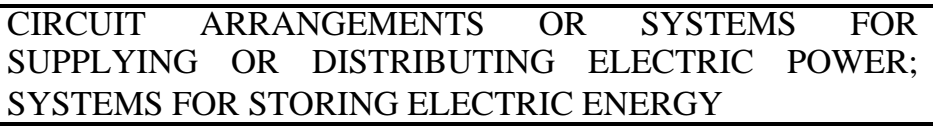 & Power Supply System \\
\hline T2 & $\mathrm{H} 02 \mathrm{M}$ & $\begin{array}{l}\text { APPARATUS FOR CONVERSION BETWEEN AC AND AC, } \\
\text { BETWEEN AC AND DC, OR BETWEEN DC AND DC, AND } \\
\text { FOR USE WITH MAINS OR SIMILAR POWER SUPPLY } \\
\text { SYSTEMS; CONVERSION OF DC OR AC INPUT POWER } \\
\text { INTO SURGE OUTPUT POWER; CONTROL OR } \\
\text { REGULATION THEREOF }\end{array}$ & Converter \\
\hline T3 & $\mathrm{H} 01 \mathrm{~L}$ & $\begin{array}{l}\text { SEMICONDUCTOR DEVICES; ELECTRIC SOLID STATE } \\
\text { DEVICES NOT OTHERWISE PROVIDED FOR }\end{array}$ & Semiconductor Device \\
\hline T4 & H01M & $\begin{array}{l}\text { PROCESSES OR MEANS, e.g. BATTERIES, FOR THE } \\
\text { DIRECT CONVERSION OF CHEMICAL ENERGY INTO } \\
\text { ELECTRICALENERGY }\end{array}$ & Conversion M ean \\
\hline T5 & $\mathrm{H} 02 \mathrm{P}$ & 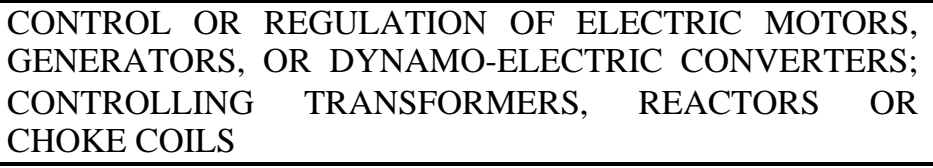 & Motor Control \\
\hline T6 & $\mathrm{H} 02 \mathrm{H}$ & EMERGENCY PROTECTIVE CIRCUIT ARRANGEMENTS & Emergency Protective \\
\hline T7 & H05B & $\begin{array}{lccc}\text { ELECTRIC } & \text { HEATING; ELECTRIC } & \text { LIGHTING } & \text { NOT } \\
\text { OTHERWISE PROVIDED FOR } & & \\
\end{array}$ & Electric Heating \\
\hline T8 & H04B & TRANSMISSION & Transmission \\
\hline T9 & H04N & PICTORIAL COMMUNICATION & $\begin{array}{l}\text { Pictorial } \\
\text { Communication }\end{array}$ \\
\hline T10 & $\mathrm{H} 01 \mathrm{~J}$ & ELECTRIC DISCHARGE TUBES OR DISCHARGE LAMPS & Discharge Device \\
\hline
\end{tabular}

Table 2: Technology Category (IPC)

\begin{tabular}{|ccll|}
\hline $\begin{array}{c}\text { Function } \\
\text { Code }\end{array}$ & $\begin{array}{c}\text { USPC } \\
\text { Class }\end{array}$ & \multicolumn{1}{c|}{ Description } & Function term \\
\hline F1 & 363 & Electric power conversion systems & Power Conversion \\
\hline F2 & 307 & Electrical transmission or interconnection systems & $\begin{array}{l}\text { Electrical } \\
\text { Transmission }\end{array}$ \\
\hline F3 & 320 & Electricity: battery or capacitor charging or discharging & Charge \\
\hline F4 & 323 & Electricity: pow er supply or regulation systems & Power Regulation \\
\hline F5 & 136 & Batteries: thermoelectric and photoel ectric & $\begin{array}{l}\text { Batteries of } \\
\text { Photoelectric }\end{array}$ \\
\hline F6 & 340 & Communications: electrical & Electrical \\
F7 & 361 & $\begin{array}{l}\text { Electricity: electrical systems and devices } \\
\text { PROTECTION, CONTROL CIRCUITS) }\end{array}$ & (SAFETY, \\
\hline F8 & 315 & Electric lamp and discharge devices: systems & Control System \\
\hline F9 & 700 & Data processing: generic control systems or specific applications & Data processing \\
\hline F10 & 438 & Semiconductor device manufacturing: process & Semiconductor D evice \\
\hline
\end{tabular}

Table 3: Function category (USPC) 


\section{Step 3: Creating technology/function matrix}

AS shown in table 4, we put the technology category (IPC) in the first column and function category (USPC) in the first row, and then we have a matrix with $n \times n$ fields. The fields of second column like TIN, T2N,..., TnN,...TION are the amounts of technology code TI(Power Supply System), T2(Converter) ,...Tn,..., TIO(Discharge Device) and
The fields of second row like FIN, F2N, ..., FnN,...FION are the amounts of function code $\mathrm{FI}$ (Power Conversion), F2(Electrical Transmission) ,...,Fn,..., FIO(Semiconductor device manufacturing). The field in the $n$ rows of $n$ columns like $\mathrm{Tn} \& \mathrm{Fn}$ is the amount of interaction of technology Tn and function Fn.

\begin{tabular}{|c|c|c|c|c|c|c|}
\hline & Function & $\begin{array}{l}\text { Power } \\
\text { Conversion } \\
\text { (F1) }\end{array}$ & $\begin{array}{l}\text { Electrical } \\
\text { Transmission } \\
\text { (F2) }\end{array}$ & Charge (F3) & $E ́(F n)$ & $\begin{array}{l}\text { Semiconductor } \\
\text { device } \\
\text { manufacturing } \\
\text { (F10) }\end{array}$ \\
\hline Technology & $\begin{array}{l}\text { A mount of } \\
\text { code }\end{array}$ & F1N & $\mathrm{F} 2 \mathrm{~N}$ & F $3 \mathrm{~N}$ & $\underline{F n N}$ & F10N \\
\hline $\begin{array}{l}\text { Power Supply } \\
\text { System (T 1) }\end{array}$ & T1N & 100 & 195 & 137 & $\mathrm{~T} 1 \& \mathrm{Fn}$ & 0 \\
\hline $\begin{array}{l}\text { Converter } \\
\text { (T2) }\end{array}$ & T2N & 232 & 71 & 23 & $\mathrm{~T} 2 \& \mathrm{Fn}$ & 0 \\
\hline $\begin{array}{l}\text { Semiconductor } \\
\text { device (T3) }\end{array}$ & T3N & 21 & 18 & 16 & T3\& Fn & 40 \\
\hline $\bar{E}(\mathrm{Tn})$ & TnN & Tn\& F1 & $\operatorname{Tn} \& \mathrm{~F} 2$ & Tn\& F3 & $\operatorname{Tn} \& \mathrm{Fn}$ & Tn\& F10 \\
\hline $\begin{array}{l}\text { Discharge } \\
\text { Device (T 10) }\end{array}$ & T10N & 1 & 4 & 0 & $\mathrm{~T} 10 \& \mathrm{Fn}$ & 6 \\
\hline
\end{tabular}

Table 4: Technology/Function matrix

In the proposed method, the $\mathrm{TnN}, \mathrm{FnN}$ and $\mathrm{Tn} \& \mathrm{Fn}$ can be obtained by patent search, the patent search strategy of "TnN", "FnN" and "Tn \& Fn" fields for the "solar power inverter" subject are below:
(A) The patent search strategy of $\mathrm{TnN}$ In the patent pool, the amount of the patents has technology $\mathrm{Tn}$ is $\mathrm{TnN}$, the figure 3 shows the logic relationship between patent pool and $\mathrm{Tn}$.

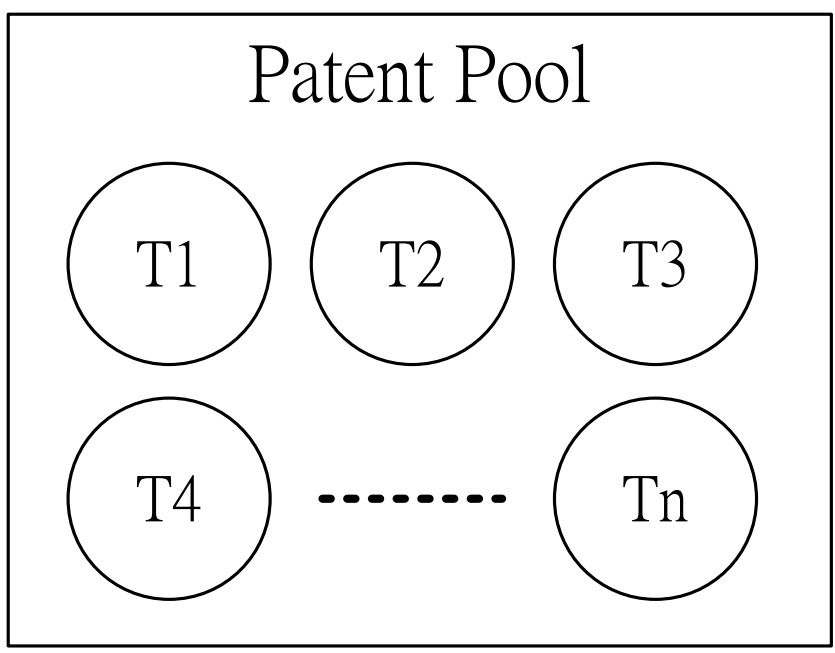

Figure 3: Logic diagram of patent pool and Tn 
We know $\mathrm{TnN}$ is the interaction of patent pool and $\mathrm{Tn}$ form figure 3, and the patent pool of the "solar power inverter" subject is searched out by the strategy that SPEC/(“"solar inverter" 3 or "Photovoltaic inverter" 3 and "PV inverter" 3 ) or ((solar or Photovoltaic) and "DC $D C$ "2)), so the patent search strategy of $\mathrm{TnN}$ is that:

SPEC/(("solar inverter" 3 or "Photovoltaic inverter" 3 and "PV inverter" 3) or ((solar or Photovoltaic) and "DC DC" 2)) and ICL/Tn.

For example, we know that TI means IPC code H02], and then we can make the patent search strategy "SPEC/ (("solar inverter" 3 or "Photovoltaic inverter" 3 and "PV inverter" 3 ) or ((solar or Photovoltaic) and "DC DC" 2)) and ICL/H02]" for "TIN" field.

(B) The patent search strategy of $\mathrm{FnN}$ fields In the patent pool, the amount of the patents has function $\mathrm{Fn}$ is $\mathrm{FnN}$, the figure 4 shows the logic relationship between patent pool and Fn.

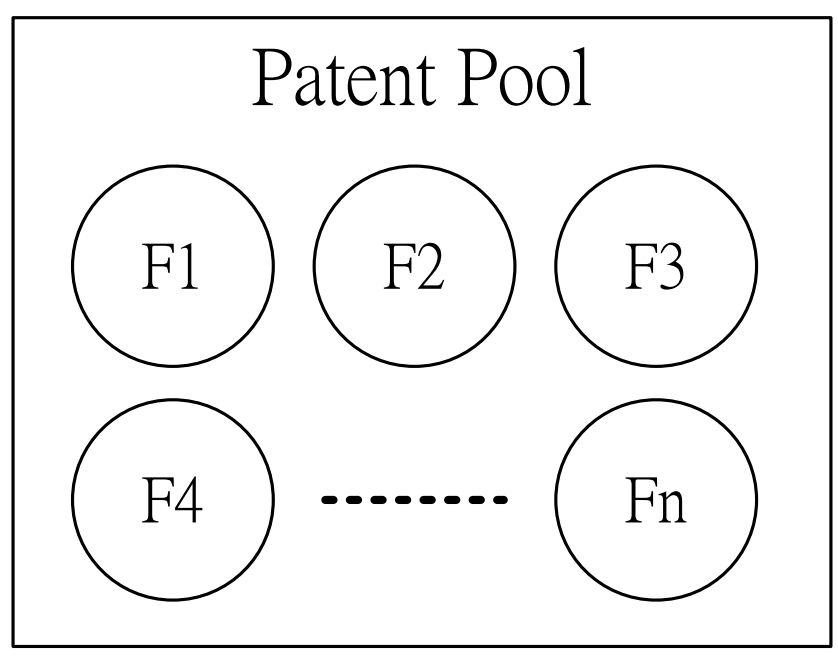

Figure 4: Logic diagram of patent pool and Fn

SPEC/(("solar inverter" 3 or "Photovoltaic inverter" 3 and "PV inverter" 3 ) or ((solar or Photovoltaic) and "DC DC" 2)) and CCL/Fn

For example, we know that FI means USPC code 363 , and then we can make the patent search strategy "SPEC/ (("solar inverter" 3 or "Photovoltaic inverter" 3 and "PV inverter" 3) or ((solar or Photovoltaic) and "DC DC" 2)) and CCL/363" for "FIN" field.
(C) The patent search strategy of Tn\&Fn fields In the patent pool, the amount of the patents has technology $\mathrm{Tn}$ and function $\mathrm{Fn}$ is Tn\&Fn, the figure 5 shows the logic relationship between patent pool, Tn and Fn.

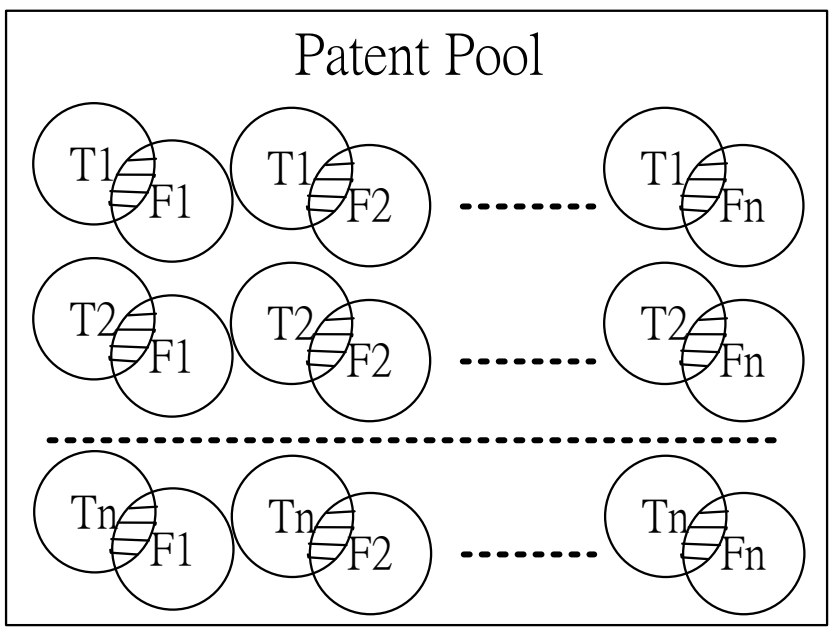

Figure 5: Logic diagram of patent pool, Tn and Fn

We know Tn\&Fn is the interaction of patent pool, Tn and Fn form figure 5 , and then the patent search strategy of Tn\&Fn is that:

SPEC/(("solar inverter" 3 or "Photovoltaic inverter" 3 and "PV inverter" 3 ) or ((solar or Photovoltaic) and "DC DC" 2)) and ICL/Tn and CCL/Fn

For example, we know that TI means IPC code H02J and FI means USPC code 363 , and then we can make the patent search strategy "SPEC/(("solar inverter" 3 or "Photovoltaic inverter" 3 and "PV inverter" 3 ) or ((solar or Photovoltaic) and "DC DC" 2)) and ICL/H02J and CCL/363" for "TI \& Fl” field.

We search out 100 patents according to the patent search strategy of " $\mathrm{TI} \& \mathrm{FI}$ ", and the number " 100 " is meaning there are 100 patents have the technology "Power Supply System" and the function "Power Conversion" of the "solar power inverter" subject. 


\section{Conclusion and Limitation}

The technology/function matrix of patent map is a powerful and useful tool for innovation and patent portfolio. But most people or company don't want to create it, because creating a technology/function matrix by traditional method is time-consuming, labor-intensive, high cost and it always needs experts' help.

We can make patent search strategy for every field easily, and complete the technology/function matrix by filling all fields of the technology/function matrix with patent search results. Accordingly, the first advantage of the proposed method is that we can dispose patents into technology/function matrix by patent search without help of experts or person has ordinary skill in the art to analyze patents. The second advantage of the proposed method is laborsaving, because we can dispose patents into technology/function matrix by patent search, and patent search just need one or few people to execute.

The best advantages of the proposed method are timesaving and low cost. Traditional method needs much manpower and experts to analyze patents, and the more patents the longer more of traditional method, actually it always takes several months. But the proposed method just needs short time to create technology/function matrix even if the patent pool has thousands of thousands of patents.

Although the proposed method has several advantages, it still has a main limitation. The main limitation of the proposed method is that, as it is based on the patent classification of IPC and USPC, and the USPC only US patents have, so the proposed method just can use to create the technology/function matrix for US patents. But WIPO, EPO, China, Japan or Korea has very abundant patents worthy to create technology/function matrix to analyze for innovation. For the purpose to obtain information of innovation from different patent database, future research can develop methods which can create technology/function matrix without the limitation of different patent database.

\section{References}

BYUNG-UN YOON, Chang-Byung Yoon and Yong-Tae Park (2002). On the development and application of a self-organizing feature map-based patent map. R\&D Management, Volume 32, Issue 4, 29I-300.

HOLGER ERNST (2003). Patent information for strategic technology management. World Patent Information. 25 (2003), 233-242.

HSIN-NING SU and Pei-Chun Lee (2009). Assessment of thermal-stable polymer nanocomposite techniques by patent citation network analysis. Journal of Business Chemistry, 6 (3), 108-125.

SHIN-ICHIRO SUZUKI (20II). Introduction to Patent Map Analysis, http://www.training-ipo.go.jp/en/uploads/ text_vtr/pdf/Introduction to Patent Map Analysis20II. pdf. [Accessed September, 15 201I].

USPTO (20II). Classification Help File: I am unfamiliar with Patent Classification. Where should I start?. http:// www.uspto.gov/web/patents/classification/help.htm. [Accessed October, 09 20II].

WIPO (2009). Patent-based Technology Analysis Report - Alternative Energy Technology. http://www.wipo.int/ patentscope/en/technology focus/pdf/landscape_alternative_energy.pdf [Accessed September, 20 20II].

WIPO (20II). INTERNATIONAL PATENT CLASSIFICATION (Version 20II): OBJECTIVES OF THE IPC. http:// www.wipo.int/export/sites/www/classifications/ipc/en/ guide/guide_ipc.pdf. [Accessed October 09 201I].

YOUNG GIL KIM, Jong Hwan Suh and Sang Chan Park (2008). Visualization of patent analysis for emerging technology. Expert Systems with Applications, 34 (2008), 1804-1812.

YUEN-HSIEN TSENG A, Chi-Jen Lin $b$ and Yu-I Lin (2007). Text mining techniques for patent analysis, Information Processing and Management, 43, 1216-1247.

ZAN HUANG, HSINCHUN CHEN, Alan Yip, Gavin Ng, Fei Guo, Zhi-Kai Chen and Mihail C. Roco (2003). Longitudinal patent analysis for nanoscale science and engineering:Country, institution and technology field. Journal of Nanoparticle Research, 5, 333-363. 
J. Technol. Manag. Innov. 20I2, Volume 7, Issue I 